\title{
ASO Visual Abstract: Initial Experience Using Magseed for Breast Lesion Localization Compared to Wire-Guided Localization-Analysis of Volume and Margin Clearance Rates
}

\author{
Roberta E. Redfern, $\mathbf{P h D}^{1}$ (D), and Robin B. Shermis, $\mathbf{M D}^{2}$ \\ ${ }^{1}$ Department of Research, ProMedica Toledo Hospital, Toledo, OH; ${ }^{2}$ ProMedica Breast Care Center, ProMedica Health \\ System, Toledo, $\mathrm{OH}$
}

Magseeds are a relatively new localization method for nonpalpable breast lesions. This analysis (https://doi.org/ 10.1245/s10434-022-11327-4) compared the resection volumes and margin negativity in consecutive cohorts undergoing wire-guided and Magseed localization. Magseed localization was associated with lower volume ratios without sacrificing margin clearance.

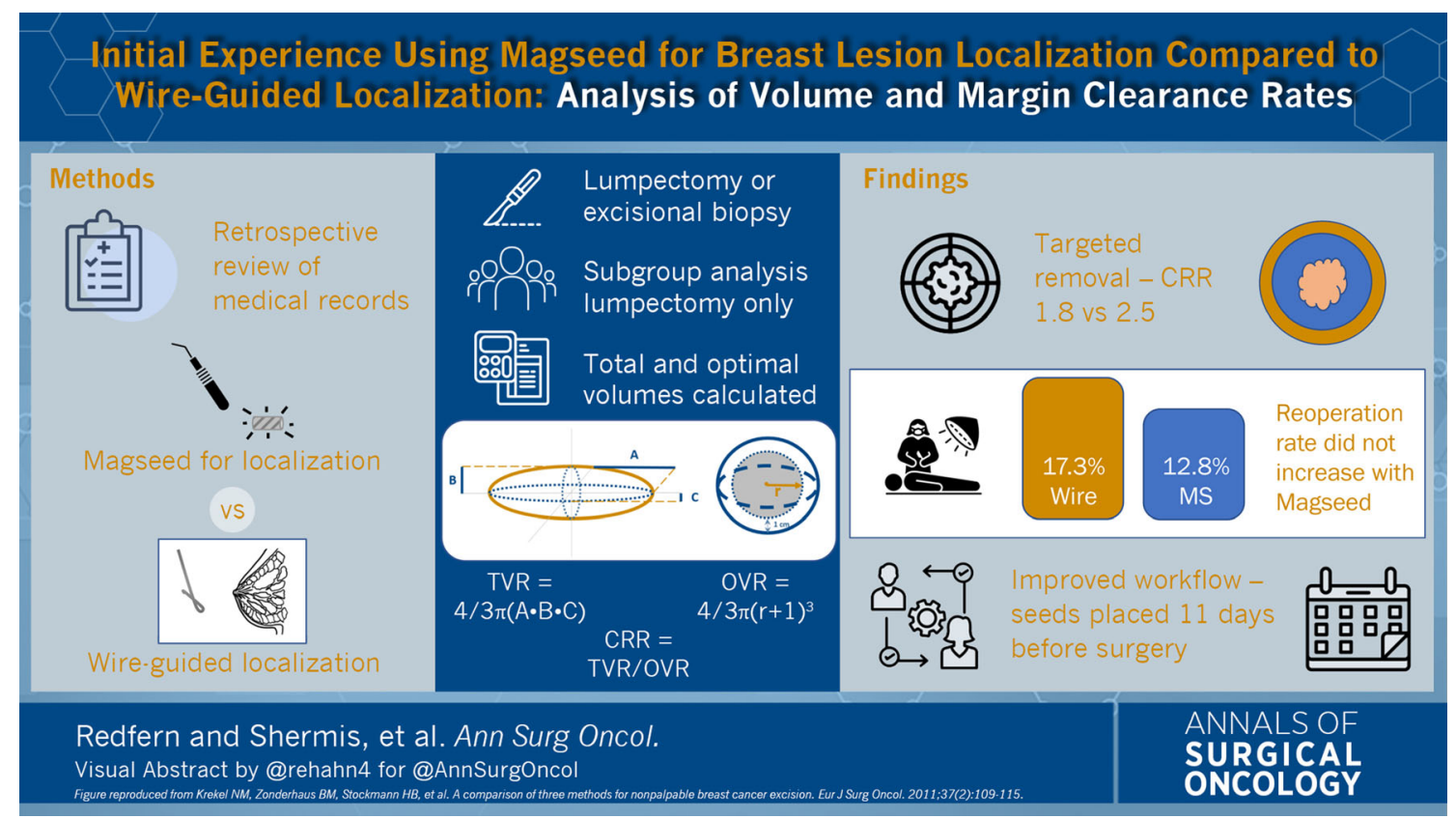

(C) Society of Surgical Oncology 2022

Published Online: 7 February 2022

R. E. Redfern, $\mathrm{PhD}$

e-mail: Roberta.redfern@promedica.org
DISCLOSURE The authors have no conflicts of interest or financial disclosures to report.

Publisher's Note Springer Nature remains neutral with regard to jurisdictional claims in published maps and institutional affiliations. 